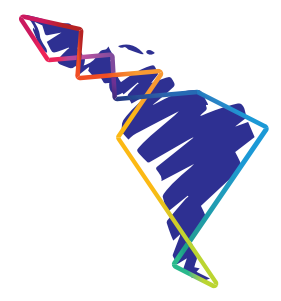

\title{
Disertaciones sobre la cultura de paz en Costa Rica
}

\author{
Dissertations on the culture of \\ peace in Costa Rica
}

\section{Dissertações sobre a cultura de paz na Costa Rica}

\section{Ronald Rivera Alfaro}

\section{Resumen}

Este artículo analiza el derecho a la paz y a la vivencia de una cultura de paz, como los ejes fundamentales de la sociedad costarricense, desde una perspectiva fundamentada o teórica de los derechos humanos como productos culturales. De esta manera, se reflexiona sobre la violación e irrespeto de los derechos humanos, fruto de visiones simplistas y reducidas resultantes del mismo orden legal, de los enfoques políticos coyunturales y del debilitamiento de la institucionalidad democrática, a partir del constreñimiento de la voluntad ciudadana. En este sentido, parte de los resultados se orientan a la elucidación de cambios sociales generadores de nuevos tejidos de significado, los cuales configuran y relaboran una complejidad más inteligible de las "obscenidades" políticas que cotidianamente son expuestas, así como un nuevo sentir y pensar de la cultura de paz que advierten de la amplitud y materialización de una perspectiva amplia de derechos humanos.

Palabras clave: derechos humanos, cultura de paz, sistema democrático, política, Centroamérica.

\begin{abstract}
The present article analyzes the right to peace and the living of a culture of peace, as the fundamental axes of Costa Rican society, from a grounded or theoretical perspective of human rights as cultural products. In this manner, it reflects on the violation and disrespect for human rights as the result of simplistic and reduced visions resulting from the same legal order, from conjunctural political approaches and from the weakening of democratic institutions,

1 Costarricense, doctor en Ciencias Sociales por la Universidad Nacional, Costa Rica. Trabaja en la División de Educación Básica de la Universidad Nacional; fue coordinador de la Maestría en Desarrollo Comunitario Sustentable y editor de la revista Perspectivas Rurales, Nueva época, ambas de la Escuela de Ciencias Agrarias. Ha publicado libros y artículos en diversos temas de la interdisciplinariedad en las ciencias sociales, seguridad ciudadana y derechos humanos. Correo electrónico: ronald.rivera.alfaro@una.ac.cr ORCID: https://orcid. org/0000-0001-9179-3517
\end{abstract}


stemming from the constraint of the citizen's will. In this sense, part of the results is aimed at elucidating social changes that generate new fabrics of meaning, which configure and rewrite a more intelligible complexity of the political "obscenities" that are exposed on a daily basis, as well as a new feeling and thinking of the culture of peace that warn of the breadth and materialization of a broad perspective on human rights.

Keywords: Human rights; Culture of peace; Democratic system; Politics; Central America.

\section{Resumo}

Este artigo analisa o direito à paz e à vivência de uma cultura de paz, como eixos fundamentais da sociedade costarriquenha, a partir de uma perspectiva fundamentada ou teórica dos direitos humanos como produtos culturais. Desse modo, reflete sobre a violação e o desrespeito aos direitos humanos, fruto de visões simplistas e reduzidas decorrentes de um mesmo ordenamento jurídico, de abordagens políticas conjunturais e do enfraquecimento das instituições democráticas, baseadas no constrangimento da vontade do cidadão. Nesse sentido, parte dos resultados visa elucidar as mudanças sociais que geram novos tecidos de sentido, que configuram e reiniciam uma complexidade mais inteligível das "obscenidades" políticas que se expõem cotidianamente, bem como um novo sentimento e pensamento. da cultura de paz que adverte para a amplitude e materialização de uma perspectiva ampla dos direitos humanos.

Palavras-chave: Direitos humanos; Cultura de paz; Sistema democrático; Política; América Central.

\section{Introducción}

La presente disertación sobre la realidad social y la historia política costarricense que ha encausado la idea de un país de paz se focaliza en analizar las decisiones políticas transcendentales, las cuales asentaron un sentido de la democracia desde la estabilidad democrática, la erradicación de la violencia y el establecimiento de una cultura de paz.

En esta línea, se realiza un acercamiento al desarrollo político que ha forjado Costa Rica desde su constitución misma como territorio, hasta los matices burocráticos que configuran un Estado asentado en una proclama de "país de paz". Esto, dentro de un espacio geopolítico lleno de contradicciones y sinsentidos como lo es Centroamérica, con golpes de Estado, guerras civiles, niveles altos de pobreza, pobreza extrema, al igual que otras violencias enmarcadas por la complacencia política y los vacíos legales, los cuales hacen que a lo interno de este escenario se reproduzcan situaciones de desigualdad social.

El abordaje metodológico consiste en la reflexión acerca de la recategorización conceptual y crítica de los derechos humanos, a partir de hechos claves y fundacionales 
de la democracia en Costa Rica. Esta perspectiva fundamentada permite establecer un enfoque crítico sobre la cultura de paz, desde una conceptualización básica de tipos de violencia, desarrollada e impulsada por la crisis democrática centroamericana, la construcción de pequeños nichos de poder político y económico, lo cual a la vez conduce al debilitamiento de la institucionalidad democrática (producto de los conflictos sociales que parten de las violaciones a los derechos humanos).

\section{Los procesos democráticos, estéticos y legales de una cultura de paz}

Solamente una visión deficitaria en el sentido de deudora y "facilona" reduciría a Costa Rica a esa ficción jurídica que el derecho internacional ejerce, por medio de sus "razones jurídicas", al regular el espacio planetario. Es por eso que Costa Rica funcionará, discursivamente ${ }^{2}$, como caja de resonancia del relato mayor (humanidad), en relación con las violencias y la crisis tanto ontológica como material del ser humano, superando así los avatares que, por "ley y razón"3, el marco normativo abstrae en sucesos que tensionan ética y moralmente el tutelaje y garantismo de los derechos humanos.

Costa Rica es una república democrática que logró su independencia en 1821, cuando dio por asentada una eterna disputa que, hasta hoy, de manera solapada, se mantiene, la cual se tensiona entre el sueño oligárquico de la anexión a algún imperio de las Américas —en su momento a México y actualmente a los Estados Unidos- y la independencia como Estado soberano. La clase oligarca, el cultivo del café y el desarrollo de una economía agraria, distinta a la del resto de Centroamérica, encaminó al país costarricense a considerase un Estado campesino, amante de la agricultura y del cuido por la naturaleza.

Su desarrollo estético se evidencia en las pictóricos de Tomás Povedano y Emilio Span, hasta la diversidad paisajística y social de Teodorico Quirós, quienes visualizan una Costa Rica colmada de cafetales y bananeras, balanceada con la iluminada San José, una de las primeras capitales con luz eléctrica en el mundo. Hasta este

2 Las relaciones entre lenguaje, ideología y ejercicio del poder son resultado de la forma discursiva en la cual se describe un hecho social en una posible dialéctica entre el suceso "discursivo particular y las situaciones, instituciones y estructuras sociales que lo enmarcan” (Wodak, 2000, p. 367). Para ello, se puede indicar que el discurso moldea e interviene de forma directa en la relación logos (conocimiento) y bios (arte de vivir), es decir, entre el ejercicio pragmático de las sociedades y las abstracciones conceptuales que estas mismas producen.

3 Las ambigüedades en el lenguaje jurídico provienen de una larga tradición grecorromana donde los razonamientos falaces interrumpen el concepto de sujeto de derecho y su posterior obligación jurídica. El orden jurídico obligatorio en el que se desenvuelve la conducta del individuo — sujeto con derechos— es invertido, en el sentido de que ahora todo el ordenamiento jurídico nacional e internacional que reconoce a un individuo como sujeto de derechos retoma sus conductas como contenido y obligación. El orden epistemológico que reordena el derecho como obra causal de un hecho estará destinado a cometer razonamientos falaciosos perpetuamente. 
punto, se puede constatar la conformación de un paisaje claro y diverso, aunque con frecuencia los objetos se transforman y adquieren nuevas identidades. Si utilizamos como pretexto la "mente dormida" de Alicia en el país de las maravillas, la sensación es que la introspección de la ciudadanía costarricense se configura mediante una razón de progreso social, a partir del trabajo y la armonía política, lo cual, por efecto inmediato, conlleva evitar el conflicto como elección racional.

La crítica literaria se movía en torno a la producción de grandes escritores arielistas ${ }^{4}$ como Carlos Luís Fallas (conocido como Calufa) y Joaquín García Monge, quienes en sus libros — principalmente Calufa — trasladaban esa realidad conflictiva de luchas sociales y discriminación. Un buen ejemplo de crítica al régimen político-empresarial es la novela Mamita Yunai, en la cual se cuenta, por medio de su personaje principal Sibajita, cómo fue la huelga bananera en la provincia de Limón en 1934, su ambiente laboral y la lucha sindical. Por otro lado, en la novela Marcos Ramírez, el autor nos narra su vida en la provincia de Alajuela, y nos deja un legado histórico de imágenes y movilizaciones sociales desde el Valle Central hasta la costa atlántica.

Desde el ordenamiento jurídico, a principio del siglo XX se presentan tres órdenes constitucionales, la primera en 1917 y dos años después la siguiente, que generó una incertidumbre en la joven nación costarricense. No es sino hasta 1949 cuando se aprueba la última constitución costarricense, la cual intentaba combatir los fraudes electorales llevados a cabo en mayo de 1948. Los actores principales fueron los bandos comandados por Otilio Ulate, del partido Unión Nacional; Rafael Ángel Calderón Guardia, del Republicano Nacional —conocido como el calderonismo- y José Figueres Ferrer, del Social Demócrata.

La génesis de lo que Costa Rica vive en el ámbito político se produce ex post guerra civil de 1948, donde el fraude electoral, la violencia política y la inmoralidad de sus actores dan presagios de una realidad que continúa haciendo estragos.

Las disputas entre el figuerismo — actualmente organizado en el Partido Liberación Nacional — y el calderonismo — partidarios de la ideología social cristiana — se desenvolvieron entre balazos y refugiados, entre ejércitos y alianzas transfronterizas. La formación de la Junta Fundadora de la Segunda República procede a establecer una serie de medidas, las cuales intentaban evitar los hechos con los que la agrupación armada ostentadora del poder utilizó, para obtener una reformulación en

4 Este legado literario antiimperialista no marxista desenmascaraba los intereses colonialistas oligárquicos de las empresas y políticos norteamericanos de la época. Dicha herencia es conocida como arielismo por el libro "Ariel" de Rodó, escrito en 1900, incentivando a las juventudes de América a reconocer y crear un espíritu latinoamericanista. 
la constitucionalidad del país y su orden gubernamental. La abolición del ejército fue una disposición aplaudida por todas las naciones; la estrategia política de no invertir en armas y mantener un ejército da el primer paso en la conformación de un estigma internacional y reputación general — tanto del gobierno como de la sociedad civil— de ser vistos como un país de paz.

De esta manera, en Costa Rica se construye una historia que permite consolidar procesos democráticos a partir de disputas sociales, permeadas, en cierto modo, por la violencia armada, que luego se transformaron en logros jurídicos sustantivos, sobre todo en materia constitucional. Ello, con la incorporación del capítulo único sobre las garantías sociales, en compensación de la vorágine con la que se instituye una clase política que logra resolver sus problemas y retos mediante una estratagema establecida con una "democracia a la tica", tal como lo argumentaba Merino del Río (1996), cuando indicaba que "el hilo conductor del progreso democrático tenía un tinte economicista” (p. 58), en concatenación con los ideales comunistas y sociales de Manuel Mora: "Comenzamos a preocuparnos por comprender los procesos históricos por medio de los cuales había cristalizado en Costa Rica lo que podríamos llamar una conciencia nacional enfocada en la democracia" (Merino, 1996, p. 60).

Es por esto, que la noción de Costa Rica como país de paz esta instituida en una reconfiguración social convenida, partiendo de una concepción de los derechos humanos cuya base se encuentra en la mediación social entre tendencias políticas polarizadas. De esta forma, es necesario debatir, brevemente, la matriz de funcionamiento social de los derechos humanos desde la óptica crítica y la elucidación de aspectos claves para el funcionamiento de los sistemas democráticos, con la supuesta violación legítima de los derechos humanos.

\section{La violación legítima de los derechos humanos}

Los derechos humanos, desde su concepción básica o tradicional, son garantizables, exigibles y tutelables solo en el entendido de la existencia de un Estado que por su poder permite sancionar el delito. Lo peligroso es que el mismo derecho es contradictorio y su línea de pensamiento - siguiendo a Locke- estructura una inmovilización de los hechos, dado que, por naturaleza, los derechos son iusnaturalistas y por hecho consustancial cualquier otra norma debe ser igual pero subordinada a la anterior.

Tanto en el hecho como en la ley, si el Estado aparece como el máximo violador de derechos, al ser ella la misma estructura de poder la que los debe hacer cumplir, se introduce una confrontación que involucra una objeción práctica. La razón 
consiste en que el cumplimiento de un derecho interfiere o puede interferir con el de otro, legitimando, de este modo, un nuevo orden que ya desde sus inicios está manipulado por un Estado totalizador.

Consecuentemente, y siguiendo el método iusnaturalista con el que se erigieron "los" derechos humanos, un determinado derecho puede llegar a mediatizar todos los demás (derecho a la vida) y, en relación con ese derecho, los otros quedan relativizados. Es por esta razón que las sociedades democráticas de hoy son las menos democráticas de la historia, se escudan bajo la falacia garantista (Herrera Flores, 2005, p. 248) de otorgar ciertos derechos bajo el no cumplimiento de los restantes.

Es así como las teorías de las democracias se centran en la promulgación y legitimación de algunos derechos sobre otros; de esta manera, se pasa de derechos humanos a la jerarquización de los fundamentales, lo cual garantiza un núcleo de poder político totalitario y universal.

Esta polarización tiene lugar en afirmar políticamente el interés general objetivo, arraigado en las relaciones de trabajo y el incremento de la producción. La aseveración de un esquema político no puede ser bajo una óptica criminal-inquisidora, que ve en la sanción el cumplimiento del derecho. La confrontación por interesarse en universalizar un beneficio generalizado es parte de un "totalitarismo democrático", es decir, el interés supremo del Estado, específicamente de sus gobernantes, quienes tienen en su bitácora un tramado de relaciones productivas que ven en el cúmulo del capital una buena gestión, un buen resultado, el cual las teorías tradicionales de la democracia observan.

Cada realidad social posee un matiz diferente, ya que no se puede promulgar, universalmente, un esquema o régimen político segregando derechos o, peor aún, jerarquizando la posibilidad de forjar una vida digna. Los esquemas productivos se legitiman en el momento en que se convierten en imperativo, por lo que la lógica que separa a las minorías del poder es la misma que entiende como criterio de la formación de realidades sociales la producción como el punto culminante de "la" democracia, aquella que vela solo por algunos derechos y que recurre a aquellos que desea eliminar en una igualdad fenomenológica. Por eso existe la necesidad de torturar y no erradicar la pobreza, dado que todo el poder político sigue el método de Locke, al determinar que el derecho inviolable e inquebrantable es el de la propiedad privada.

Por consiguiente, el sistema de la propiedad privada y de la conducción de la economía se convierte en el lado visible del ejercicio democrático de un Estado, 
pero, en el fondo, el poder político del supuesto Estado democrático tiene su raíz en este ciclo de jerarquización e inversión de los derechos humanos.

La visión crítica del derecho es consciente de que la ley es prescriptiva, en el sentido en que declara el deber ser y no asienta el hecho como algo real, tangible en la existencia, y de que, a partir del dogmatismo que difunde el Estado por medio del discurso oficial, se convierte en ley divina, e involuciona así en la formulación de sus posibilidades concretas.

La participación de la sociedad es clave para el repensar de la democracia y el ejercicio propio del Estado, sin jerarquías ni reversiones. Entonces, afirmar los derechos humanos es reafirmar la vida inmediata, que a su vez significa y testifica, políticamente, la vida humana como una lucha social por la particular concepción de la dignidad y que, como consecuencia de la casi inevitable inversión del derecho, presenta en sí una ofuscación semiológica que separa el derecho del deber.

Tomando en cuenta lo expuesto, nuestro foco de estudio es el país centroamericano con mayores posibilidades y obligaciones tanto de protección como de tutelaje de los derechos humanos y, para este fin, abordaremos brevemente la región donde se encuentra y su impacto en los procesos de pacificación regional.

\section{Algunos baches en Centroamérica}

Preludio de una utopía en la que el presente nos regaña y enceguece con muestras concretas de violencias causadas y recibidas por la misma humanidad, con golpes de Estado y asesinatos, la segunda mitad del siglo XX y las primeras décadas del siglo XXI se desenvuelven en una dicotomía peligrosamente maniquea entre la democracia formal y la democracia real en Centroamérica. Lo formal se satisface con la existencia de un Estado de derecho, con un espacio colmado de normas, reglamentos, leyes e instrumentos que, según las bases epistemológicas de su creación, deben ser respetados, indivisible e inherentemente, por lo cual un "ciudadano" puede encontrar defensa legal de sus derechos. Por otro lado, la democracia real estaría enfocada en la diversidad de sujetos quienes, en supuesto caso, pueden ejercer "formalmente" y en igualdad de condiciones sus derechos políticos. En abstracto, la democracia no puede ser tal si existe violencia represiva del Estado, ya sea militar o políticamente. Asimismo, la democracia en Centroamérica ha desembocado en varias vertientes, las cuales al final convergen en la democracia vista por sus resultados y no por su desarrollo ético, social y cultural que, en dado caso, también se podrían cuantificar con la creación de indicadores, pero que en ninguna circunstancia estarían libres de objeciones y mejoras. 
Desde 1987, los países centroamericanos, por medio de sus gobiernos, lograron poner un breve freno a sus diferencias ideológicas y han intentado, a través de un escrito legal, vinculante en todos sus sentidos, poner fin al conflicto armado. Lo anterior, donde la disputa este-oeste avasallaba sin ninguna contemplación las naciones que, por algún tipo de interés estratégico — personal o comunitario—, se promulgaban simpatizantes del socialismo. Treinta años después, algunos actores vuelven a ocupar espacios de poder absorbente y, como crónicas de una muerte anunciada, los enfrentamientos con intervencionismo militar vuelven a la región centroamericana. Esta vez le correspondió al país con mayor injerencia militar norteamericana de la región, Honduras. En el 2009, este vio cómo los intentos de construir una democracia, siguiendo los senderos de la convivencia pacífica, han caducado en un avergonzante golpe de Estado a su entonces presidente Manuel Zelaya, mediante la fuerza militar del Estado y la proclamación, al día siguiente, de un presidente de facto quien funda sobre la cabeza de la población la idea de que nadie podrá hacer cambios en lo que consideran un texto sagrado: la constitución. Este hecho que marca un rebobinamiento de la violencia despótica se ha desarrollado, con mayor dureza, nueve años después, en el 2018 en Nicaragua, donde se erige un capítulo con " 545 muertos en un salvaje enfrentamiento entre militares, grupos paramilitares, estudiantes universitarios y otros grupos manifestantes" (Romero, 2019). Ocurrió por la imposibilidad de dialogar sobre la reforma al sistema de pensiones y a la imposición de una rebaja del $5 \%$ a la pensión de las personas jubiladas decretada por el Gobierno del presidente Daniel Ortega, por recomendación del Fondo Monetario Internacional (idem).

Ha sido al final del siglo XX y principios del XXI cuando los remanentes de los acuerdos de paz apuntalan a demostrar que la democracia formal es pieza fundamental de una jugada política asentada en el capitalismo rural o, mejor dicho, en una consolidada oligarquía y en la sacralización de la representatividad política como última palabra. Esto, sin importar las circunstancias por las cuales las demandas ciudadanas se ahogan en intereses partidarios que contradicen el acto de asociación implícito en la labor del legislador, cuyo compromiso debe ser recíproco, y los derechos contraídos crean obligaciones en un claro principio del derecho civil.

Es en el conjunto de los movimientos sociales y la crisis política que surge un debate primeramente teórico, que luego ve en el desarrollo de la Revolución sandinista el centro de las disputas por los ejes polarizados del conflicto (este-oeste), donde las fuerzas populares forman un proyecto para la constitución de un nuevo régimen democrático.

Las condiciones que necesita Centroamérica para desarrollar la democracia parten de la experiencia histórica de sujeción y revoluciones, de cómo el capitalismo, 
genéricamente, se ha implantado en la región y establecido relaciones económicas de dependencia. En consecuencia, aunque se hable de la democracia costarricense y la autoritaria política-militar del resto de Centroamérica, la verdad es que la consolidación de la economía agraria y su desarrollo a posteriori ha sido uno de los puntos clave de diferenciación. Por lo demás, incluso el atrevimiento militar es en conjunto, ya que, en la década de los setenta, el territorio fronterizo de Costa Rica funcionaba como campo de entrenamiento militar para el sandinismo.

De esta manera, la democracia liberal centroamericana estaba orientada a la construcción de pequeños circuitos económicos para la producción interna que, junto a la presencia de capital extranjero, permitió transitar a la implantación de un sistema oligárquico, esta vez funcionando por medio del ejército, articulando las instituciones legales y autoritarias con regímenes políticos conservadores.

En los procesos históricos de formación de derechos, desde el contrato social rousseauniano hasta la Declaración Universal de los Derechos Humanos, ha existido un desbalance entre el derecho como "un supuesto" indivisible e inalienable y quién es sujeto de este. La formulación del principio de comunidad en Rousseau no somete los límites del soberano que por "dominio real", puesto que es soberano, está activo y se separa o diferencia del súbdito, quien está sometido a las leyes. Ante lo anterior, se plantea que: "quien redacta la ley no tiene, pues, o no debe tener, ningún derecho que es inalienable” (Rousseau, 1987, p. 81). Así, el ser soberano estaría por encima de las leyes, o bien no se incluye en el alcance de estas. Un derecho es proclamado inalienable en el sentido de "esencia" que pierde su historia y complejidad cultural; el surgimiento semántico de los derechos humanos mediante la declaración con el mismo nombre, en 1948, posee ese tipo de contradicción, aunque su carencia epistemológica no desmerita su desarrollo a posteriori.

En los ochenta, El Salvador hospedaba, por medio del Frente Farabundo Martí para la Liberación Nacional (FMLN), unos 3000 hombres armados; en Nicaragua, la contra norteamericana creó graves fallos en la economía, puesto que debían enfrentar la guerra calificada de baja intensidad, con alrededor de 8300 hombres en el ejército popular sandinista; en Guatemala, el ejército contaba con 15000 soldados regulares y 9000 paramilitares. La lógica contrainsurgente estaba orientada a reproducir de forma tardía el poder tradicional — la soberanía—, por lo que, en crisis similares a la de los ochenta con la aproximación militar-electoral en Honduras y Nicaragua, se recrean los problemas que enfrentaron los países centroamericanos dos décadas atrás, con sus diferencias, pero con bases violentas de parecida magnitud. 
Por su parte, una adormecida sociedad hondureña vivió momentos de tribulación al cierre de la primera década del siglo XXI. Con un supuesto Estado de derecho "nuevo", con elecciones legislativas y presidenciales desde los ochenta, el país centroamericano se ha caracterizado por ser uno de los territorios más desiguales en América Latina, con casi un 60 \% de habitantes en situación de pobreza y una inestabilidad militar inherente a su historia (Gallardo, 2009, p. 2).

Contradicción institucional o violencia militar es lo que sufren los Estados centroamericanos, donde la voluntad de unificar criterios a costa de infundir temor no es, en absoluto, un método nuevo. Los vacíos, portillos y paradojas legales que hemos logrado describir sin mayor dificultad con los casos de Honduras y Costa Rica muestran, una vez más, que la autoridad política adormece la participación social en momentos en los cuales se tensionan los intereses y se relega el respeto por la institucionalidad democrática en beneficio de la reproducción capitalista, lo que hace inviable cualquier proceso de emancipación.

La inagotable metáfora del "Leviatán" —Dios mortal—, fundada por Hobbes, recobra interés y nos ayuda a colocar en tela de duda el fin del Estado, cuya estrategia continúa siendo la de crear el terror que hace posible tanto unificar las voluntades como lograr la paz.

Las imágenes de terror para legitimar la conservación de un Estado endiosado permiten comprender la disputa que tan siquiera ronda los debates correspondientes al "valor supremo" kelseniano o a las querellas inmanentes de la acumulación de la riqueza y existencia de esta en Marx. La lógica política actual se hunde en la "alabanza" a los mecanismos de obediencia que eufemísticamente se han denominado gobernabilidad.

En resumen, la violencia directa que sufre la política costarricense se basa fundamentalmente en (1) el debilitamiento de la institucionalidad democrática; (2) la inmoralidad de las personas en política (quienes asientan el miedo y la desvergüenza), y (3) el supuesto Estado de bienestar que cada vez cede más terreno ante el inminente crecimiento de un enervamiento de alarma social, el cual proyecta un caos político que, al parecer, subyacentemente, afianza un Leviatán sediento de poder.

Las personas en política - tal como lo vemos hoy- justifican la existencia de un Estado de derecho plagado de instrumentos legales que, según las bases epistemológicas de su creación, deben ser respetados incondicionalmente, debido a su indivisibilidad e inherencia a la ficción de Estado y, por lo tanto, a la ficción de ciudadanía. La existencia de un Estado democrático involuciona recurrentemente 
en Costa Rica, no solo por ser interpretado como súplica de unos cuantos sujetos a una entidad "todopoderosa" que, en vez de defender y proteger, mata, sino que además es partícipe directa de la falacia garantista. Esta última se entiende como aquella que se jacta de sonreír bajo el escudo protector de un "manto sagrado" que venera el "imperativo de la ley" como base del bien/estar social, sustentando, de este modo, la continua masacre de la vida en el planeta.

El fenómeno de la democracia parte, en una primera visión, de un sistema político que, en su estructura epistémica y axiológica, se guía por un "universalismo" o sacralización de "los" derechos humanos, esos que, por concesión graciosa, primeramente, el hombre y hoy "casi" toda la humanidad posee. Es por esto por lo que la línea de pensamiento que peligrosamente universaliza ciertos derechos se encuentra desde la teoría democrática de Locke, Rousseau y Marx-Lenin, es decir, desde una lógica de oposición binaria que pretende universalizar, por el simple hecho de la crítica, el sistema político de enfrente. Todas (las anteriores) discuten sobre los resultados de un régimen democrático, pero ninguna ve en sí los mecanismos electorales, mientras se dedican a tomar como válida la escogencia de las mayorías.

\section{Conclusión}

Consecuentemente, a modo de conclusión, es necesario establecer las bases sobre los cuales se pueda fundar una cultura de paz, a partir de la integración de la norma jurídica y del respeto a todas las formas de participación ciudadana, incluidos los nuevos sujetos sociales, o movimientos emergentes, que advierten de la amplitud y materialización de una perspectiva amplia de derechos humanos.

La primera base es la complejidad de la sociedad y sus tensiones. Esta premisa teórica que aborda al Estado, a la sociedad y al mercado en el ámbito de la democracia se caracteriza por tres rasgos sobresalientes. El primero se encomienda a la dificultad de la sociedad y sus presiones internas con respecto al relativo cumplimiento de sus derechos, por lo tanto, la creciente diferenciación en los niveles micro y macro en los distintos campos de la vida social. Ello ha impulsado, en segunda instancia, a los abusos del poder político estatal y al desgarramiento entre la regulación gubernamental y las diferentes manifestaciones sociales, donde la capacidad jurídica disminuye y se afianzan medidas agresoras llamadas de "mano dura", acompañadas

5 Se plantea que "casi" todas las personas poseen derechos, debido a que, en la realidad del ejercicio concreto, en algunas de ellas, según el momento (pobreza, enfermedad) y el lugar (Estado), la exigibilidad del derecho es causa perdida. Inclusive, dicha solicitud se ve truncada por el mismo ejercicio de la ley; como ejemplo claro, el artículo 26 de la Convención Americana de Derechos humanos, el cual dice que, de acuerdo con los alcances del Estado, los derechos económicos y sociales quedan a disposición de este, a modo de desarrollo progresivo. 
del libre mercado como parte de la racionalidad medio-fin ${ }^{6}$. Por último, la tercera premisa se orienta al conflicto ético entre la intercambiabilidad de la vida humana inserta en los procesos de globalización, como medio de los procedimientos de modernización, cuya conducción se define a sí misma como estrategia para lograr una mayor competitividad, gracias a la crisis del Estado "keynesiano" y el asentamiento de una integración transnacional de mercados.

Un concepto integrado por la norma jurídica y el respeto a todas las formas de participación ciudadana y no ciudadana, junto a la justicia social, es parte de una visión de derechos humanos, que manifiesta una clara incomodidad con el tan proclamado universalismo de los derechos; una universalidad abstracta que crea un ser humano disconforme con los procesos impuestos de forma ritualizada.

En este sentido, las sociedades costarricenses comienzan a generar una serie de tejidos de significado que configuran y reelaboran una complejidad más inteligible de las "obscenidades" políticas, las cuales cotidianamente son expuestas por los medios de comunicación.

Esta configuración de significados pasa por la invención de una nueva iconografía que representa el sentir humano. Un ejemplo es la dirección de imagen que sufren las campañas políticas, debido al abstencionismo en las urnas electorales de los últimos años. Se muestra que la disminución del ejercicio del voto permite afirmar que la representatividad de la ciudadanía es mayor cuanto menor sea su número de representados, lo cual desestabiliza o interfiere, por definición, en los intereses propios de los representados, puesto que el interés general no puede coincidir con el de todos.

La validación de una imagen pulcra, intachable, en quien confiar la seguridad del país es la plataforma que sustenta una candidatura presidencial. Atrás quedaron los discursos sobre la alegoría del ser costarricense de quienes, reunidos con un café, daban el apoyo incondicional al bipartidismo.

El "Estado democrático", la ciudadanía civil y política como fundamento de creación del Estado y la confusión pragmática por brindar seguridad han subsumido los conceptos de acción ciudadana, participación o movimiento social en una nueva lógica de "cambio" que, en su sentido más estricto, no es más que un restablecimiento de "otros" espacios de opinión política organizada.

6 Aun cuando las agresiones de los derechos sean evidentes, el discurso oficial (el que tiene el poder de designar lo que se tiene que hacer) prefiere violar, amputar y exterminar, sin ningún miramiento, la libertad de las personas, antes que cuestionar cómo se genera riqueza. 
Así, es posible dar referencia de varios acontecimientos que definen y engloban conflictos enlazados a desgarramientos entre "lo" democrático, justo y razonable, y las tensiones que la "justicia" crea a partir de la lucha entre "los" derechos de la ciudadanía con respecto a las omisiones y transgresiones de los nuevos sujetos. Parte de estos conflictos son muestras de temas recurrentes que con el paso de los años se han consolidado como prácticas que relativizan los derechos, ocultan la impunidad ${ }^{7}$ y obscenamente subyacen en la clase política costarricense. Los ejemplos que a continuación se enunciarán sin mayor detalle son el preámbulo de la dinámica hegemónica mecanicista que fortalece la percepción de inseguridad de la "ciudadanía" costarricense.

Los brotes de violencia directa aparecían cada vez que se confrontaban discursos que, por medio de mecanismos implícitos, supuraban un bienestar innegable. La labor de la Sala Constitucional de Costa Rica, en respuesta a las consultas emitidas por la Asamblea Legislativa, dividió las opiniones de la sociedad costarricense y constituyó el desplome de las bases comunicantes entre el sector trabajador, a su vez fraccionado, y el hueco fiscal y hundimiento de las finanzas públicas.

La segunda base son las subjetividades emergentes. Es el ligamen o fundamento que tiene este reconocer la diversidad del ser humano y los movimientos sociales parte de la necesaria apertura y posterior consolidación de espacios de lucha, en pro de la dignidad humana. Igualmente, intervienen el compromiso y la afirmación de las diferencias que fungen como motor de un impulso social, el cual no considera la vida ni la dignidad — los derechos humanos - como algo ya conseguido o establecido de una vez y por todas, sino como algo por conseguir.

Asimismo, los instrumentos jurídicos se han encargado de reconocer ciertos grupos en situación de vulnerabilidad y lograr, mediante acciones afirmativas, un trato equitativo, en su praxis del derecho como un instrumento esencial para la reconstitución del tejido social, de garantía y consolidación de las luchas sociales por la dignidad humana. Esto se ha traducido en leyes —a través de una transferencia de poder convalidada por los movimientos sociales—, una lógica marcada por un círculo simbólico y discursivo alrededor de subjetividades reconocidas.

Por tanto, la interrogante sobre la tensión o el desgarramiento existente en el interior del ejercicio político se da por medio de la visibilización de la exclusión social

7 Desde Pinochet hasta Trump, la impunidad es inmoralmente constatable, el uso de las violencias tiene asidero en cualquier discurso sin importar su fundamento. Los crímenes de lesa humanidad no solo se dan en casos como los citados, en cada gobierno, específicamente en América Latina, donde la relativización de la vida es pan de cada día. La agresión directa a pueblos indígenas en Guatemala, el lucro con la pobreza de las tan afamadas favelas brasileñas, la venta indiscriminada y aberrante de naturaleza en Costa Rica son algunos casos de la crisis mundial de "los" derechos humanos. 
("la ciudadanía" como sujetos de derechos) y del enrarecimiento discursivo (el fundamento moderno del derecho construido a partir del individualismo de Locke y el Estado de Hobbes funcionan para limitar las acciones estatales), donde "el" mismo ciudadano (Rousseau) ritualiza el habla (establecen quiénes son sujetos de derecho $)^{8} \mathrm{y}$, con ello, genera/generaliza mecanismos de rechazo, con el fin de amputar todo intento de emancipación social.

La concentración de poder político, específicamente en Costa Rica como reflector de la realidad latinoamericana, ha llevado a olvidar el carácter esperanzador y dignificador de los derechos humanos que, mediante su labor jurídica, tutela y garantiza los derechos, trata por todos los medios posibles (discursos) de desmantelar la consolidación de una "obediencia civil" (Gallardo, 2008, p. 92). Con ello, se traslapa toda protesta - o sea, subjetividad emergente- como acto de indisciplina, soberbia, traición o simplemente desacato ante el imperativo de la ley (el país corre el riesgo de ser inseguro).

Finalmente, la forma de concebir los derechos humanos, desde el análisis del contexto con el propósito de hacer inducciones generalizables hasta la idea de acción concreta en el ser humano como responsable de sus actos, permite orientar la acción política para el asentamiento de una cultura de paz.

La idea es actuar desde lo provocativo, de incomodar los esquemas rígidos encargados de limitar emociones, pensamientos y acciones de las personas con modelos mentales diferentes, tanto en la política como en la economía, la estética y la sexualidad, con el fin de exterminar la discriminación y las falsas promesas de bienestar, así como de conseguir un verdadero reconocimiento no supeditado a las leyes ni a los esquemas de socialización actuales. Se trata, pues, de crear espacios nuevos de convivencia, donde no se tengan que remendar lo sesgos del pasado, sino que se renueve el hábitat vivencial en una radicalización ética-ontológica. El fin es que la ética se focalice en las ideas y el discernimiento de un tramado social que no solo es el ejecutor de las ideas de los otros, sino la raíz del desarrollo comunal; es "poner a la gente primero" y provocar una acción subversiva.

Esta libertad de formas trae consigo un nuevo diálogo en el que la ley no es el elemento fuerte en la sociedad, sino es parte de una serie de instrumentos vigentes que pueden ayudar a romper con la "barrera" de la figura verticalista de poder. Lo anterior, en el intento de una deconstrucción para conformar una mejor calidad

8 Es necesario recordar que las luchas feministas en el ámbito de lo político, comandadas en primera instancia por Mary Wollstonecraft en el siglo XVIII (coartífice intelectual de la "Declaración Universal de los Derechos del Hombre y el Ciudadano"), abogaban por el reconocimiento de sus derechos civiles y políticos, en otras palabras, por ser consideradas "ciudadanos". 
de vida, donde la visibilización de las diferencias sea provechosa y desarrolle un impacto positivo en el pensamiento de la humanidad, no solo como contemplación hacia un razonamiento nuevo, sino como todo un proceso creativo de valoración incompleta de la sociedad, en el que la innovación empiece por concebir y ejecutar una socialización inclusiva.

\section{Referencias}

Asamblea Legislativa. (2004). Ley Contra la Corrupción y el Enriquecimiento Ilícito en la Función Pública, ley 8422. Recuperado de http://www.pgrweb.go.cr/scij/Busqueda/Normativa/Normas/nrm_texto_ completo.aspx? param1 =NRTC\&nValor $1=1 \&$ nValor $2=53738 \&$ nValor $3=90841 \&$ strTipM=TC

Gallardo, H. (2008). Teoría crítica: Matriz y posibilidad de Derechos Humanos. San Luis Potosí, México: Comisión Estatal de Derechos Humanos. Facultad de Derecho, Universidad Autónoma de San Luis Potosí.

Gallardo, H. (2009). Notas sobre el Golpe de Estado en Honduras. Recuperado de www. pensamientocritico.info

Herrera-Flores, J. (2005). Los derechos humanos como productos culturales. Crítica al humanismo abstracto. Madrid: Catarata.

Merino, J. (1996). Manuel Mora y la democracia costarricense. Heredia, Costa Rica: Editorial Fundación UNA.

Romero, E. (2019). ANPDH eleva a 545 la cifra de muertos por la represión en Nicaragua. La Prensa. Recuperado de https://www.laprensa.com.ni/2018/11/24/ nacionales/2499471-anpdh-eleva-a-545-la-cifra-de-muertos-por-la-represion-en-nicaragua

Rousseau, J. J. (1987). El contrato social. Traducción de Juan Mario Castellanos. Sexta edición. San José: EDUCA.

Wodak, R. (2000). Análisis crítico del discurso. El discurso como interacción social. Barcelona: Editorial Gedisa. 
